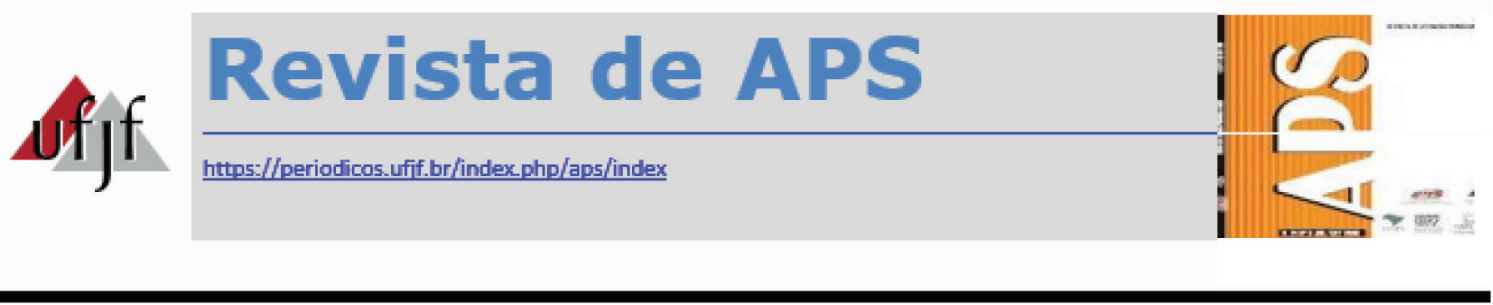

\title{
Vulnerabilidade de mulheres às infecções sexualmente transmissíveis e câncer de colo uterino em uma unidade prisional
}

\author{
Women's vulnerability to sexually transmitted infections and cervical \\ cancer in a prison
}

Jorge Luis Tavares de Oliveira ${ }^{1}$, Zuleyce Maria Lessa Pacheco ${ }^{2}$, Cristina Arreguy

Senna ${ }^{3}$

\begin{abstract}
RESUMO
Objetivo: Compreender estado de vulnerabilidade de mulheres em condição de reclusão de uma instituição prisional acerca das infecções sexualmente transmissíveis e câncer de colo de útero. Método: Pesquisa qualitativa exploratória alicerçada no referencial conceitual de vulnerabilidade individual, social e programática realizada com 28 mulheres em reclusão. Dados coletados de forma cursiva por formulário e tratados por análise de conteúdo temático-categorial. Resultado: Emergiram duas categorias: Percepções e compreensão das reclusas sobre infecções sexualmente transmissíveis e medidas adotadas para preveni-las e Práticas educativas e concepções sobre prevenção das infecções sexualmente transmissíveis e câncer de colo de útero. Conclusão: Há fragilidades no sistema prisional relacionadas à efetividade de ações educativas, preventivas e assistenciais perante a saúde reprodutiva e sexual das mulheres em reclusão. A equipe multiprofissional juntamente com o enfermeiro necessita efetivar ações preventivas e educativas nas prisões para evitar o adoecimento dessa população vulnerável da mesma maneira que são realizadas nas unidades básicas de saúde da rede pública.
\end{abstract}

PALAVRAS-CHAVE: Saúde da mulher. Vulnerabilidade em saúde. Doenças sexualmente transmissíveis. Neoplasia intraepitelial cervical. Enfermagem.

\footnotetext{
${ }^{1}$ Enfermeiro, Mestre em Enfermagem Universidade Federal de Juiz de Fora (UFJF), doutorando em Saúde Pública (Fiocruz).E-mail: jorgektarin@yahoo.com.br

${ }^{2}$ Enfermeira, Doutora em Enfermagem (UFRJ), Professora Adjunta da Faculdade de Enfermagem da Universidade Federal de Juiz de Fora.

${ }^{3}$ Enfermeira, Doutora em Enfermagem (USP), Pós-doutora pela Universidade Nova de Lisboa. Professora Associada da Faculdade de Enfermagem da Universidade Federal de Juiz de Fora.
} 


\begin{abstract}
Objective: To understand the vulnerability condition of women in prison concerning sexually transmitted infections and cervical cancer. Method: A qualitative exploratory research based on the conceptual framework of individual, social and programmatic vulnerability carried out with 28 women in prison. Data collection took place in a cursive way by form and was interpreted by thematic and categorical content analysis. Result: Two categories emerged: Prisoners' perceptions and understanding of sexually transmitted infections and measures taken to prevent them, as well as Educational practices and concepts on the prevention of sexually transmitted infections and cervical cancer. Conclusion: There is some fragility in the prison system related to the effectiveness of educational, preventive and assistance actions concerning reproductive and sexual health of women in prison. The multi-professional team, together with the nurse, must carry out preventive and educational actions in prisons to prevent the illness of this vulnerable population the same way they are carried out in basic public health units.
\end{abstract}

KEYWORDS: Women's health. Health vulnerability. Sexually transmitted diseases. Cervical intraepithelial neoplasia. Nursing.

\title{
INTRODUÇÃO
}

A representação de mulheres na população prisional brasileira, quando comparada à dos homens, tende a ser numericamente pouco expressiva, embora a reclusão em si seja um evento indesejável. A média brasileira é 4,94\% (36.929) de mulheres presas para 95,06\% (711.080) de homens. Dados do Departamento Penitenciário Nacional (DEPEN) evidenciam redução da taxa de mulheres em condição de reclusão entre 2014 a 2019. ${ }^{1,2}$

Entre 2005 a 2014, essa taxa cresceu numa média de 10,7\% ao ano. Em termos absolutos, a população feminina saltou de 12.925 pessoas presas em 2005 para 33.793 em 2014, sendo notórias as condenações por crimes relacionados às drogas, categoria composta por tráfico de drogas e associação para o tráfico ${ }^{1,2}$ Entre julho e dezembro de 2019, a população carcerária de mulheres em números absolutos era de 31.938 , se comparados aos dados de 2014, houve redução de 5,48\%. ${ }^{1}$

Essa população possui características sociais e demográficas peculiares, ${ }^{2,3}$ caracterizadas pela presença de mulheres jovens, de nível socioeconômico e educacional baixo, desempregadas, solteiras ou separadas, procedentes de centros urbanos, com mais de um filho e com deficiência de acesso aos serviços de saúde. ${ }^{1-5}$ Ao comparar a distribuição entre homens e mulheres no sistema prisional, destaca-se a maior frequência de crimes ligados ao tráfico de drogas entre as mulheres. A população de mulheres em reclusão da cor/raça parda e preta é de $66,7 \%{ }^{1}$

As mulheres em condições carcerárias possuem comportamentos e hábitos de vida singulares, possuindo necessidades de saúde que devem ser atendidas por meio de ações assistenciais, educativas e programáticas, pois estão mais susceptíveis ao adoecimento do que mulheres em liberdade. ${ }^{3-5} \mathrm{~A}$ saúde da mulher 
é um dos desafios para a efetiva implementação de políticas públicas do Sistema Único de Saúde (SUS) no sistema prisional. As limitações impostas por barreiras institucionais e intramuros, com inúmeras violações e constrangimentos a que as mulheres em situação de reclusão são submetidas, produzem riscos, danos físicos, psicológicos e morais. ${ }^{3}$

Associa-se a esse perfil o sistema prisional como centralizador de condições que favorecem a aquisição de doenças infecciosas, com alta prevalência do vírus da imunodeficiência humana (HIV), hepatites e demais infecções sexualmente transmissíveis (IST). Dentre os fatores que contribuem para a disseminação de IST nas prisões estão: promiscuidade e abuso sexual, relacionamento bissexual e homossexual, superlotação e uso de drogas. ${ }^{3-5}$

O sistema prisional brasileiro é considerado um complicador de saúde pública, devido à inadequada infraestrutura, as condições sanitárias precárias e o contingente prisional excessivo em relação à capacidade das penitenciárias, o que provoca superlotação das celas e favorece a disseminação descontrolada de doenças infectocontagiosas. ${ }^{2-4,6,7}$ Outra consideração se refere às características biológicas inerentes à mulher, que as tornam suscetíveis às diversas doenças, sejam aquelas de transmissibilidade ou condicionadas por fatores hormonais, imunológicos, genéticos e ambientais. ${ }^{8,9}$

A deficiência de programas governamentais focalizados nessa população faz com que se torne mais susceptível ao acometimento por infecções e doenças, dificultando abordagens que reduzem a vulnerabilidade das mulheres encarceradas frente às IST, dentre essas a infecção pelo HIV e do papilomavírus humano (HPV), precursor do câncer de colo de útero (CCU). ${ }^{3,4,8,9}$

O acesso da população em reclusão às ações e serviços de saúde é um dos fatores que dificultam a prevenção de doenças, apesar da garantia pela Constituição Federal de 1988 do direito legal e constitucional à saúde. ${ }^{10}$ Salienta-se que em 2003, através do trabalho conjunto entre os Ministérios da Saúde e da Justiça, foi lançado o Plano Nacional de Saúde no Sistema Penitenciário (PNSSP), instituído pela Portaria Interministerial no 1777/2003, sendo revogada, com a publicação da Política Nacional de Atenção Integral às Pessoas Privadas de Liberdade no Sistema Prisional (PNAISP), instituída pela Portaria Interministerial no 01/2014, prevendo a estruturação de Unidades Básicas de Saúde (UBS) nos estabelecimentos prisionais. , $^{3,4,10-12}$

Com a PNAISP no âmbito do SUS, as unidades prisionais são reafirmadas como pontos de atenção básica no contexto da Rede de Atenção à Saúde (RAS) do sistema público de saúde, com oferta de uma assistência integral, resolutiva e contínua às demandas de saúde, com controle e redução dos agravos mais prevalentes no ambiente carcerário. Com isso, as pessoas privadas de liberdade com IST, inclusive HIV, devem ser assistidas por equipes internas das unidades prisionais que precisam desenvolver ações conforme 
atribuições e funções da Atenção Primária à Saúde (APS), com encaminhamentos para atendimentos em outros pontos de atenção, quando necessário. ${ }^{4}$

Ao instituir a PNAISP, garantiu-se uma organização para o acesso dessa população tutelada pelo Estado às ações e serviços de saúde do SUS de forma integral, universal, equânime e contínua. ${ }^{4}$ Como objetivo geral da PNAISP tem-se a garantia do acesso das pessoas privadas de liberdade no sistema prisional ao cuidado integral, com as unidades prisionais sendo consideradas como unidades de saúde da atenção básica, estabelecendo a porta de entrada no SUS, caracterizada por um conjunto de ações individuais e coletivas, abrangendo a promoção e a proteção da saúde, a prevenção de agravos, o diagnóstico, o tratamento, a redução dos danos e a manutenção da saúde com desenvolvimento de estratégias que tenham impactos positivos na situação de saúde dessa população considerada vulnerável. ${ }^{10-12}$

A vulnerabilidade é concebida como "a chance de exposição das pessoas ao adoecimento como a resultante de um conjunto de aspectos não apenas individuais, mas também coletivos, contextuais, que acarretam maior susceptibilidade à infecção e ao adoecimento". ${ }^{13: 123}$ As análises de vulnerabilidade devem englobar aspectos desde a susceptibilidade orgânica até mesmo a implementação das políticas públicas e organização dos serviços de saúde, em conjunto com condicionantes comportamentais, culturais, sociais, econômicos e políticos. Integram-se em três eixos interdependentes de compreensão dos aspectos das vidas dos indivíduos, das comunidades ou, até mesmo, de países, considerando-as susceptíveis. São essas a vulnerabilidade individual, a social e a programática. ${ }^{13,14}$

A vulnerabilidade individual (biológica) relaciona-se com o comportamento das pessoas. Ela depende do grau e da qualidade de informações de que cada indivíduo dispõe sobre determinado assunto ou tema, à capacidade de utilizar essas informações em benefício da sua saúde e incorporá-las nas práticas cotidianas, transformando-as em medidas de prevenção e de promoção a saúde efetivas. ${ }^{13-15}$

A vulnerabilidade social refere-se ao conjunto de fatores sociais que fragiliza o acesso aos bens e serviços de saúde, ao conteúdo e qualidade de informações oferecidas aos indivíduos, e assim, condiciona determinado grupo social à exposição ou não aos riscos em um contexto socioambiental. ${ }^{13-15}$ Por último, a vulnerabilidade programática (institucional) está relacionada às ações que o poder público, iniciativa privada e organizações da sociedade civil empreendem, ou não, no sentido de reduzir as chances de ocorrência de enfermidades, bem como garantir a qualidade dos bens e serviços prestados à população e ao monitoramento desses. ${ }^{13-15}$

Dessa forma, pressupõe que mulheres em condição de reclusão são mais vulneráveis às IST e ao adoecimento, constituindo-se uma população com dificuldade em ter acesso aos bens e serviços de saúde básicos, tais como recebimento de informações sobre IST, à realização dos exames citopatológicos e mamografias periodicamente. Tendo 
as unidades prisionais a obrigatoriedade de ofertar essas ações de cunho preventivo, de promoção à saúde, o tratamento e de recuperação à saúde, ${ }^{3,5,6}$ a presente investigação objetiva compreender o estado de vulnerabilidade de mulheres em condição de reclusão de uma instituição prisional em um município mineiro acerca das IST e CCU.

\section{MÉTODOS}

Pesquisa qualitativa do tipo exploratória ${ }^{16}$ realizada em uma unidade prisional do estado de Minas Gerais realizada com 28 mulheres em regime fechado de reclusão.

Atendendo aos critérios de comportamento e condutas adotadas como aceitáveis na unidade prisional do ponto de vista da triagem institucional, obtevese uma amostra por conveniência. Foram critérios de participação: mulheres em reclusão no regime fechado da unidade prisional; alfabetizadas; que aceitaram participar da pesquisa como voluntárias não remuneradas; maiores de 18 anos, autorizadas pelo responsável da instituição para integrar a investigação. Foram critérios de exclusão: não atender aos critérios de inclusão e não ser autorizada sua participação pelo regime disciplinar da instituição.

As participantes foram recrutadas na ocasião em que estavam no pátio do pavilhão para banho de sol no período da manhã e tarde, sendo direcionada individualmente a biblioteca do pavilhão feminino, com escolta de agentes penitenciários. Foi realizada entrevista semiestruturada sem interferência institucional, mantendo no local destinado à pesquisa apenas o entrevistador e a participante convidada.

Os dados foram coletados através de entrevistas individuais realizadas no período de 30 de julho a 27 de agosto de 2014. Foi utilizado como instrumento de coleta um formulário composto por caracterização das participantes e quatro questões norteadoras: Quando fala de doenças ou infecções sexualmente transmissíveis você pensa ...)?; Quando fala em proteção da mulher para doenças transmitidas por sexo você pensa (...)?; Quais os meios de informação que você teve sobre infecções sexualmente transmissíveis (síndrome da imunodeficiência adquirida - AIDS, hepatite, HPV) ou doenças ligadas a sexo e ao gênero feminino (câncer de colo de útero, de mama, etc.) antes de vir para cá?; e Quais as informações que teve/tem sobre a prevenção do câncer do colo de útero aqui? Aplicou-se o formulário (pré-teste) em três entrevistas prévias à pesquisa propriamente dita para validar a facilidade em compreender as respectivas questões e as respostas oriundas dessas. As informações obtidas dessas entrevistas foram desconsideradas da pesquisa.

Os critérios da legislação do sistema prisional foram atendidos, neles constam que é expressamente proibido gravações de imagens e voz, e utilização de aparelhos eletrônicos (celular, câmeras e gravadores) no interior das instituições prisionais, sendo 
os registros dos dados realizados na forma cursiva pelo entrevistador. Após o registro dos relatos, eram lidas as respostas registradas, visando à confirmação dos relatos pelas participantes. Em situações nas quais os relatos não condiziam exatamente com o que havia sido expressado, eram refeitos e apresentados às participantes, para que confirmasse o nexo, a lógica e o sentido textual apresentado por elas.

Os dados coletados foram consolidados no programa Word for Windows e a análise das informações deu-se através do método de análise de conteúdo proposto por Bardin, atendendo as seguintes etapas: pré-análise, exploração do material ou codificação e tratamento dos resultados, inferências e interpretação dos dados. ${ }^{17}$

Autores têm definido diferentes tipos de técnicas que podem ser adotadas para o desenvolvimento de análise de conteúdos, as quais divergem em si, pela maneira como é realizada a exploração do material analisado a partir das observações de diferentes elementos textuais. ${ }^{18,19}$

Neste estudo optou-se pela análise de conteúdo temático-categorial, que foi desenvolvida através de um conjunto de procedimentos sistemáticos respeitando o rigor metodológico que a técnica exige. Para operacionalizar a análise de conteúdo temático-categorial, foram adotadas as seguintes etapas: leitura flutuante; definição de pressupostos provisórios sobre o objeto estudado e o texto analisado; determinação das unidades de registros; definição das unidades de significação ou temas; análise temática das unidades de registros; análise categorial do texto; tratamento e apresentação dos resultados e discussão dos resultados e retorno ao objeto de estudo. ${ }^{18}$

A coleta e análise dos dados foram realizadas em concomitância. Utilizando-se critério de similaridade de conteúdos na estruturação das unidades de significado e identificação das categorias, estruturou-se o fechamento amostral a partir de critérios de saturação teórica. ${ }^{19,20}$

As análises das informações possibilitaram a caracterização sociodemográfica das participantes e emergiram duas categorias temáticas: Medidas de proteção e prevenção para IST e Práticas educativas e informações adquiridas para prevenção de IST e CCU.

Algumas informações sobre rotinas, assistência à saúde no interior e fora da unidade prisional e sobre equipes dos profissionais foram registradas em diário de campo e incorporadas indiretamente ao estudo. A qualidade das informações da pesquisa foi verificada por meio da aplicação do Consolidated Criteria for Reporting Qualitative Studies (COREQ), ${ }^{21}$ com alcance de 30 itens dentro dos 32 solicitados (desconsiderou a utilização de gravação de aúdio ou visual para coleta de dados e não foi aplicado na análise dos dados um software específico).

O estudo foi aprovado pelo Comitê de Ética em Pesquisa da Universidade Federal de Juiz de Fora sob o número do parecer 701.600 em 26/07/14 (CAAE 32153914.0.0000.5147). Foram atendidos os requisitos éticos e legais de pesquisa 
envolvendo seres humanos em consonância com a legislação atual preconizada na Resolução no466/2012.22

\section{RESULTADOS}

\section{Caracterização sociodemográfica}

Participaram do estudo 28 mulheres em situação de reclusão com idade entre 19 e 50 anos, com média de idade de 34,5 anos. Quanto à escolaridade declarada, houve variação entre um ano e 12 anos de estudo, com prevalência de oito anos de estudo. A maioria das mulheres eram heterossexuais, casadas e pardas. Em relação à renda familiar, as participantes declararam receber entre um e dois salários mínimos e participar financeiramente no núcleo familiar. No que se refere à condição judicial, a maioria das participantes declararam estar em reclusão devido ao tráfico de drogas e já haviam sido julgadas.

\section{Medidas de proteção e prevenção para IST}

As informações obtidas sobre as percepções e conhecimentos das reclusas sobre as IST e a prevenção dessas doenças possibilitaram o surgimento da categoria "Medidas de proteção e prevenção para IST".

Frente à vulnerabilidade das mulheres em condição de reclusão e com o conhecimento de que as infecções transmitidas por via sexual são uma realidade dentro do sistema prisional, ${ }^{3-6}$ perguntou-se às participantes sobre o que pensavam das doenças ou infecções transmitidas sexualmente. Através dos relatos, constatou-se que as reclusas possuíam preocupação e medo em relação ao HIV/AIDS. As respostas foram justificadas por ser essa uma doença incurável, por ter vivenciado a morte de pessoas conhecidas ou familiares pelo HIV/AIDS e por ser uma doença transmitida através das relações sexuais (sexo).

"[...] As pessoas tem que se cuidar mais. [...] HIV, eu penso nela. Por que é uma doença que não tem cura. A mais apavorante que têm é ela, a AIDS. Perdi muitos amigos por causa dela." (R8)

"[...] Ah! Eu penso que a pessoa tem que se cuidar mais [...], se proteger na hora da relação [...]. Como foi o caso do meu filho. Pegou HIV. Não tomou cuidado." (R22)

Também se percebeu o medo das participantes no que se refere à aquisição e transmissão de outras doenças transmitidas sexualmente.

"Eu tenho medo. Tenho medo de pegar doença. Tudo menos uma doença transmitida. [...] Eu penso que é horrível pegar uma doença dessas por ter sexo com uma pessoa. É horrível." (R27) 
As participantes relataram que a aquisição e transmissão das IST e HIV/AIDS é uma condição normal, sendo passível de serem adquiridas caso as pessoas não adotem cuidados com o próprio corpo, não busquem informações e não realizem medidas de prevenção.

"Ah! Eu penso que isso aí é uma falta de cuidado, tem tanto meio de prevenção. Antigamente não tinha como evitar, mas hoje em dia, tem mais condições de evitar essas doenças [...]" (R11)

"Penso que é uma coisa normal, qualquer um pode pegar se não se prevenir." (R12)

A partir dos relatos foram identificadas as medidas de proteção (prevenção) que adotavam em relação às IST, as participantes citaram a utilização de preservativos/ camisinha, a realização de exames sorológicos e Papanicolau (Preventivo), cuidado com o próprio corpo e manutenção de parceiro fixo.

"Usar camisinha e fazer tratamento para vê se tem algum tipo de doença. Fazer exame para HIV, de sífilis. Eu faço lá no posto." (R3)

"Preventivo. Camisinha. O essencial é o preventivo e a camisinha." (R18)

"Ah! Eu não faço nada, porque tenho meu parceiro certo, mas se eu não tivesse usaria camisinha." (R20)

Constatou-se que as reclusas sabem da necessidade de medidas de prevenção às IST, uma vez que são temerosas ao HIV/AIDS e demais IST. Essas foram consideradas vulneráveis à aquisição e à transmissão das doenças transmitidas por via sexual dentro das instituições prisionais, como HIV/AIDS e sífilis. Foi identificada a assistência prestada pelos profissionais da APS em relação às IST com oferta de exames para HIV e sífilis na UBS da rede pública municipal.

\section{Práticas educativas e informações adquiridas para prevenção de IST e CCU.}

Sabe-se que as ações educativas são ferramentas eficazes para a prevenção a agravos à saúde, ${ }^{3-6}$ sendo assim, perguntou-se às participantes quais seriam os meios e os conteúdos das informações que tiveram sobre IST, doenças ligadas ao sexo e ao gênero feminino (câncer de colo de útero, câncer de mama) antes e durante a permanência no sistema prisional.

As participantes relataram ter obtido informações acerca das IST, doenças ligadas ao sexo e ao gênero feminino, especificamente, quando participaram de palestras e grupos educativos direcionados aos direitos sexuais e reprodutivos (Planejamento Familiar) nas UBS da rede pública de saúde. Também tiveram acesso às informações através de televisão, informando-se com familiares e/ou conhecidos e na escola. Essas informações foram obtidas antes do período de reclusão conforme descrito pelas participantes. 
"Minha tia, desde pequena nos ensinava, porque ela era enfermeira. Ela levava folhetos para nós. HPV, como fica depois. Dava palestras para nós na escola [...]" (R5)

"Entendo mais dessas doenças transmissíveis. Eu tive umas palestras (Grupo de Direitos Sexuais e Reprodutivos) no posto médico, para eu começar a tomar injeção. Também já vi propaganda na televisão. Às vezes minhas amigas comentam." (R6)

"Pelo direito reprodutivo, a gente aprende muita coisa, aí eles ensinam muita coisa para prevenir DST, prevenir filhos, prevenir câncer de colo de útero. Ensina o outro, o das mamas e a se tocar." (R20)

Em relação às doenças relacionadas ao gênero feminino, como CCU e câncer de mama, as participantes relataram que durante a permanência na prisão nenhuma abordagem educativa foi realizada, de modo a orientá-las ou informá-las sobre essas doenças.

"Aqui nenhuma não. Já foi falado de hepatite, AIDS, pela enfermeira da unidade há bastante tempo." (R6)

"Aqui dentro nada. Aqui eles não têm palestras. Não tem nada." (R18)

As informações obtidas a respeito dessas doenças foram por meio da participação em palestras ou grupos educativos com a temática de direitos sexuais e reprodutivos oferecidos pela rede pública na APS. Foi relatado pelas participantes que em outras unidades prisionais do Estado eram realizadas atividades educativas com cunho preventivo, onde aconteceram palestras que informavam as reclusas sobre as características, sintomas das IST e visualização de órgãos do sistema reprodutor acometidos por essas infecções. O profissional de saúde responsável por essas atividades foi referido como a enfermeira. Não foram ofertadas informações, orientações e esclarecimentos nessa unidade prisional onde as reclusas permaneciam.

Ressalta que a oferta dessas informações dentro sistema prisional é bastante variável, sendo dependentes das condições das unidades prisionais ou das equipes multiprofissionais. Constatou-se que as informações foram inexistentes na maioria dos relatos, sendo descrito pelas participantes que a aquisição de informações aconteceu no tempo em que estiveram detidas em outras prisões.

"Lá em M. [outro município] a gente assistia a muitas palestras, com a enfermeira chefe que explicava [...]. Aqui nessa penitenciária não tive nenhuma [município da pesquisa], não tive informação de nada, nem livros, nem palestras, nem nada." (R4)

"Nenhuma. Aqui nunca deram palestras (município da pesquisa). Lá em C. [outro município], elas davam. Colocava até telão, mostrava o útero para nós, o HPV. Aquele negócio para fora [condilomas]. Aquele líquido amarelado quando estava avançado [leucorreias]." (R5) 
Sobre o conteúdo das informações oferecidas às participantes, seja através das palestras e grupos educativos, seja por familiares e/ou conhecidos e na televisão, relataram ter aprendido acerca do HIV/AIDS, HPV (verrugas), corrimentos, CCU, câncer de mama e as formas de preveni-los.

"[...] Eles explicam para gente que muitas pessoas não sabem o que é HIV. O que é um câncer de útero. Cada um fala um pouco da sua vida, vida própria. [...] Os enfermeiros e os médicos explicam sobre o câncer, HPV, HIV." (R2)

"[...] Falavam de DST e os modos da mulher pegarem. Como ela vai saber que tem verrugas, corrimento. Modo de se prevenir. Se ocorrer, correr para o médico." (R21)

As participantes do estudo obtiveram informações em relação às doenças transmitidas sexualmente e as doenças relacionadas ao gênero feminino, principalmente, em UBS antes de serem presas. As informações foram obtidas através de palestras e grupos educativos com a temática direitos sexuais e reprodutivos no nível primário de atenção, reforçando a importância da APS no empoderamento das mulheres e aquisição de conhecimentos e informações sobre as medidas de prevenção às doenças que envolvem o aparelho reprodutivo feminino e os comportamentos promotores de saúde.

\section{DISCUSSÃO}

Os indivíduos estão expostos à aquisição e a transmissão de doenças infectocontagiosas dentro do sistema prisional, pois há uma multiplicidade de fatores físicos e psicológicos que favorecem essa condição. ${ }^{3-6,23}$

O sistema prisional brasileiro por si só é um facilitador para que os indivíduos em situação de reclusão tornem-se predispostos aos diversos agentes biológicos que possam comprometer a sua integridade e sua saúde, colocando-os em risco de adquirir infecções e/ou desenvolver doenças, distúrbios mentais, doenças infecciosas, doenças crônicas e sexualmente transmissíveis, como sífilis e HIV. ${ }^{4,23-25}$ Apesar da existência de políticas públicas relacionadas à população prisional, como o PNSSP e a PNAISP, essa continua inatingível ou excluída das ações de saúde no âmbito do SUS, tornando-se mais vulnerável frente às condições precárias das prisões e as dificuldades de acesso. ${ }^{23}$

A publicação do PNAISP objetivou organizar o acesso dos recolhidos, nas unidades prisionais masculinas e femininas, às ações e serviços do SUS. O PNAISP reforça que a atenção à saúde deve ser integral, humanizada e organizada na própria unidade prisional, uma vez que a saúde é um direito universal do indivíduo, por meio de estratégias e serviços básicos, a serem prestados por equipes multidisciplinares compostas por diferentes profissionais de saúde. 10,11,23,24

Sabe-se que mulheres em situação de reclusão possuem características peculiares distintas das mulheres em liberdade. Tais peculiaridades condicionam a 
sua vulnerabilidade, seja no âmbito social ou individual, havendo diversos fatores que interferem no acesso às informações, serviços e bens de saúde. . $^{3-6,23-25}$

Vulnerabilidade individual é compreendida como o grau e a qualidade de informações de que cada indivíduo dispõe sobre determinado assunto, sendo capaz de utilizar medidas a fim de aplicá-las no cotidiano, visando melhorar seu bem estar ou manter seu estado de saúde. ${ }^{13-15}$ Quando se trata de mulheres encarceradas, apenas ter conhecimento sobre determinado tema não é suficiente para evitar a aquisição de infecções, tornando-as bastante dependentes do sistema prisional, estando as reclusas à mercê de ações realizadas pela equipe de saúde, sendo essas pontuais, fragmentadas e em sua maioria direcionadas ao sexo masculino. ${ }^{3-7}$

Outros fatores que favorecem a vulnerabilidade das mulheres em condição de reclusão podem ser citados como aqueles relacionados ao gênero, como as relações de desigualdades entre mulheres e homens, falta de informações referentes à sexualidade e desconhecimento do próprio corpo, dificuldade em se ter relações sexuais seguras e utilização de preservativos nas relações sexuais, condições biológicas, socioeconômicas e culturais. ${ }^{3-6,23}$

Evidenciou-se, em um estudo transversal realizado em Mato Grosso, a existência de uma predominância do comportamento heterossexual dentro das prisões, porém a prática homossexual tem se tornado comum, em especial entre as mulheres. Os motivos citados para essa mudança comportamental são referidos como a necessidade maior de relacionamento afetivo, melhor enfrentamento das mulheres durante a sua permanência no cárcere e preservação de afetos. Esse comportamento é considerado um fator de risco para a transmissão de IST, devido às práticas sexuais entre as mulheres, com compartilhamentos de objetos eróticos e demais práticas sexuais sem medidas de proteção favorecendo a transmissão de doenças. Essas práticas sexuais são significativas no contexto de análise, pois estão associadas à falta de percepções pelas mulheres em reclusão de suas vulnerabilidades, uma vez que a aquisição de IST, em geral, está ligada à figura masculina. ${ }^{6}$

O risco de adoecimento por câncer cervical uterino eleva-se entre mulheres que dispõem de baixo nível educacional e socioeconômico. Mulheres com baixo nível de instrução apresentam maior susceptibilidade agravando as vulnerabilidades individuais e coletivas, compondo um fator de risco social considerável para o desenvolvimento do CCU. Ao referir-se à vulnerabilidade individual, essa envolve tanto a dimensão comportamental quanto a cognitiva ligada ao acesso e compreensão das informações. Ressalta-se que essas mulheres podem ter sido privadas de oportunidades para elucidar dúvidas e questões pertinentes a sexualidade e comportamentos preventivos às IST, deixando de adquirir conhecimentos e orientações. ${ }^{4,5}$

Ao analisar as características socioeconômicas e culturais encontradas nessa investigação, percebe-se uma compatibilidade com dados encontrados na literatura 
nacional. ${ }^{3,4,6,23}$ Denota-se que as participantes são em sua maioria mulheres jovens, com baixo nível socioeconômico, renda entre um a dois salários mínimos, baixa escolaridade e têm como motivo da reclusão o envolvimento com tráfico de drogas. ${ }^{1-3}$

Frente às descrições encontradas no estudo, constatou-se que as ações preventivas, quando implementadas, são realizadas de forma fragmentada e pontual. Na maioria das vezes, não possuem nenhuma atividade educativa, não sendo capazes de oferecer informações referentes à saúde sexual e reprodutiva às mulheres em situação de reclusão, sendo esse um achado deste trabalho. Dessa forma, não são oferecidas práticas educativas acerca de IST, HIV/AIDS e doenças relacionadas ao gênero feminino (câncer de mama e $\mathrm{CCU}$ ), dificultando às mulheres presas, com condições socioeconômicas desfavorecidas e com baixo nível de escolaridade, adotar medidas de prevenção, contrapondo o que é estabelecido em legislações pertinentes a esse grupo. 5,6,10-12,23-25

Ressalta-se que a assistência à saúde da mulher no contexto dos presídios restringe-se apenas às consultas ginecológicas e distribuição de preservativos, esses quando são implementados pelas equipes multiprofissionais. A assistência às mulheres acontece de forma reduzida, já que essas ações dependem de transporte, escolta e do deslocamento das presas até os serviços de saúde, dentro ou fora das instituições prisionais. ${ }^{10,12,23,24}$

A elaboração da linha de cuidado direcionada às medidas de prevenção na transmissão de IST, especialmente do HIV, no âmbito prisional, permeia a possibilidade do acesso, diagnóstico e do tratamento nos serviços de saúde das mulheres em reclusão, quando necessário. As Equipes de Atenção Básica prisional (EABp) devem envolver-se em ações educativas como a distribuição de panfletos, disposição de cartazes informativos e estratégias de educação em saúde com metodologias ativas, visando informar e facilitar o acesso às ações de prevenção para IST e HIV em um ambiente propício aos comportamentos de risco, com prática sexual desprotegida e uso de drogas. ${ }^{4-6}$

Todo processo educativo necessita de envolvimento dos indivíduos para alcançar o sucesso, e assim, todas as partes envolvidas devem participar ativamente desse processo. Os indivíduos que demandam conhecimentos para realizar as mudanças nos seus comportamentos e hábitos de vida precisam compreender e sensibilizar-se sobre essa necessidade e os profissionais que atuam nas unidades prisionais femininas precisam planejar ações estratégicas em prol da prevenção de IST e doenças ginecológicas que acometem as mulheres, como oCCU e o de mama, abordando questões referentes ao gênero com oferta de orientações e esclarecimentos. As mulheres em cárcere são historicamente vulneráveis, por possuírem práticas sexuais desprotegidas no âmbito dos relacionamentos bissexuais, homossexuais e heterossexuais nas prisões, restrito conhecimento acerca da sua saúde sexual e reprodutiva e não adoção de medidas de proteção. ${ }^{3-6}$

Ressalta-se que o fortalecimento da autonomia dos indivíduos é à base do processo educativo, considerando que os saberes e percepções dos sujeitos devem ser 
consolidados mediante ao contexto no qual está inserido, seja esse ambiental, social, econômico ou emocional. ${ }^{3,5,6,23}$

As ações e os serviços destinados à população encarcerada devem priorizar a implantação de medidas que promovam a saúde e prevenção de doenças. Toda ação preventiva nas instituições prisionais deve considerar os atores envolvidos nesse processo, seja para as mulheres na condição de reclusão, familiares, visitantes ou pelos que realizam visitas íntimas e os funcionários. Podem ser realizadas através de atividades educativas e assistenciais visando à sensibilização frente às IST, a não utilização de drogas, compartilhamentos de materiais eróticos e perfurocortantes. ${ }^{23-25}$ Evidências apontam a insuficiência de informações e conhecimentos incorretos acerca de questões relacionadas aos riscos e práticas de saúde pelas mulheres no cárcere ${ }^{3-6}$. Na perspectiva das reclusas, os profissionais de saúde do sistema prisional envolvidos na assistência à saúde têm contribuído para a permanência dessas práticas errôneas e prejudiciais, justificando sua culpa a partir da ineficácia de suporte assistencial integral, quando em suas ações cotidianas representam o fazer em saúde a partir de iniciativas fragmentadas que não incluem ações de promoção, prevenção e recuperação da saúde, diferente do que é realizado nas UBS da rede pública ${ }^{3}$ e do que é previsto na PNAISP. ${ }^{10-12}$

A infecção pelo HIV e, consequentemente, o adoecimento pela AIDS representam uma ameaça à integridade e à saúde sob todos os aspectos. Essa é uma das doenças sexualmente transmissíveis mais preocupante devido ao seu caráter pandêmico e sua gravidade, sendo esse também um achado nesta investigação, considerando que é um grave problema de saúde pública. ${ }^{3,23-25}$

Em uma revisão sistemática e meta-análise com integração de 72 estudos que relataram a prevalência de HIV para 2.275 .930 prisioneiros adultos do sexo masculino e feminino, a estimativa combinada da prevalência de HIV foi de 3,4\% (IC 95\% 3,2\% $-3,6 \%)$. A prevalência de HIV em estudos individuais nos países que compunham a revisão possuía variações discrepantes, variando de zero na Bósnia e Herzegovina a mais de $20 \%$ no Irã, Zâmbia, Espanha. A prevalência de HIV entre prisioneiros na Ásia, África, América do Norte e Europa foi estimada em 3,0\% (IC 95\% 3,3\%-4,3\%), 6\% (IC 95\% -0,0\%2,0\%), 4\% (IC 95\% 3,0\%-4,0\%) e 5,0\% (IC 95\% 0,0\%-11\%), respectivamente. ${ }^{26}$ Esses dados corroboram a necessidade de efetivar políticas e estratégias de prevenção ao HIV/AIDS e as IST dentro do sistema prisional em todo o mundo. ${ }^{23-25}$

Em outra revisão sistemática, com abordagem sobre o risco de aquisição do HIV e o vírus da hepatite C (HCV) entre pessoas que injetam drogas, com integração de 20 estudos e resultados não publicados de outros 21 estudos, com origens da Ásia, Austrália, Europa, América do Norte e Latina, o processo de encarceramento recente associou-se a um aumento de $81 \%$ (risco relativo [RR] 1,81, IC 95\% 1,40-2,34) no risco de aquisição de HIV, com heterogeneidade moderada entre os estudos $\left(I^{2}=63,5 \% ; p=\right.$ 0,001), e um aumento de $62 \%$ ( $R R 1,62,95 \%$ Cl 1,28-2,05) no risco de aquisição de HCV, 
também com heterogeneidade moderada entre os estudos $\left(I^{2}=57,3 \% ; p=0,002\right)$. $O$ encarceramento anterior foi associado a um aumento de $25 \%$ no risco de aquisição de HIV (RR 1,25, IC 95\% 0,94-1,65) e um aumento de $21 \%$ no risco de aquisição de HCV (RR 1,21, IC 95\% 1,02-1,43). Os resultados do estudo corroboram que o encarceramento associa-se a aumentos substanciais de curto prazo no risco de aquisição de HIV e HCV entre os prisioneiros que utilizam drogas e pode ser um fator significativo de transmissão de HCV e HIV, o que demanda das instituições prisionais desses países a necessidade de desenvolvimento de novas intervenções para minimizar o risco de aquisição de HCV e HIV, incluindo a abordagem dos riscos estruturais associados às leis de combate as drogas e encarceramento excessivo. ${ }^{27}$

Outro fator de risco para a infecção do HIV e demais IST é apresentado com as relações sexuais desprotegidas durante a permanência das mulheres nas unidades prisionais ou durante as visitas íntimas com seus parceiros(as). Essas são significativas na transmissão de IST nas prisões no Brasil, sendo a via sexual a principal responsável pela transmissão do HIV entre pessoas em reclusão. ${ }^{3,6,23-25}$ Além dos fatores já citados, as instituições prisionais possuem inúmeros condicionantes que possibilitam a aquisição de IST entre as presidiárias, os quais perpassam os comportamentos de risco adotados por elas durante a permanência na prisão, pois possuem histórico de práticas sexuais sem proteção, baixo nível de escolaridade, restrito conhecimento de práticas preventivas e baixas condições socioeconômicas. . $-6,23-27^{-27}$

Nesta investigação, detectou-se que as participantes possuíam conhecimentos acerca da transmissão e aquisição das IST, em especial HIV/AIDS, bem como o receio e a preocupação em adquirir essas infecções. Há estudos com apontamentos sobre mulheres encarceradas apresentarem maior probabilidade de ter sofrido violência de gênero ou possuir histórico de comportamentos e práticas sexuais não seguras antes de serem encarceradas, ${ }^{3,4,6,23,25}$ colocando-as em situação de vulnerabilidade social antes mesmo de estarem presas. . $13,14,23,25$ Os comportamentos e práticas sexuais adotados pelas mulheres antes de serem presas e nas prisões são considerados fatores determinantes e que trazem preocupação em relação às IST. ${ }^{3-6}$

As relações sexuais desprotegidas dentro das prisões expõem os indivíduos às IST, o que torna a utilização de preservativos (camisinha) uma necessidade dentro dessas instituições, tanto com a finalidade contraceptiva como preventiva à aquisição das IST. ${ }^{3-6}$ Estão previstas no PNAISP, além da realização de ações educativas (aconselhamento e esclarecimentos), também ações preventivas, diagnósticas, assistenciais e o tratamento para às IST. ${ }^{4,9,23,25}$

Apesar disso, há duas grandes dificuldades a serem superadas sobre o controle de IST, especialmente, em relação ao uso de preservativos nas instituições prisionais: a dificuldade na distribuição dos preservativos e a correta utilização dos preservativos pela população encarcerada. Há uma fragilidade no conhecimento acerca da utilização 
correta dos preservativos por mulheres presas, sendo as informações consideradas superficiais. Ressalta-se que a utilização correta do preservativo apresentou pouca representatividade devido à inconsistência do uso. ${ }^{4}$ Vale lembrar que a principal medida de proteção em relação às IST e HIV relatada pelas participantes neste estudo referia-se à utilização de camisinha (preservativo) quando utilizada.

Assim, para garantir o acesso à saúde pela população encarcerada e reduzir a vulnerabilidade programática, é necessário que as instituições civis da sociedade que trabalham com a temática dos direitos humanos no sistema penitenciário, juntamente com gestores públicos responsáveis por essa área, elaborem e executem medidas mais significativas em relação às ações preventivas e assistenciais à saúde. ${ }^{23,25}$ Essas ações reduzem as chances de ocorrências de enfermidades, garantem a qualidade dos serviços prestados pelas instituições e monitoram os programas de controle de disseminação de doenças infectocontagiosas no sistema prisional. Ao adotar estratégias, essas devem ser pareadas como as ações realizadas pelas UBS, como a realização de grupos educativos, palestras, panfletos informativos, cartazes explicativos (planejamento familiar, gravidez indesejada e a prevenção de IST, CCU e de mama) e adoção de práticas assistenciais (consultas médicas, de enfermagem, exames citopatológicos, mamografias e realização de exames periódicos)..$^{8,9}$

Em uma revisão sistemática com integração de 42 estudos, em 21 estudos com desfechos de prevalência foi descrita uma taxa de prevalência mais alta de displasia cervical e câncer nas mulheres de sistemas prisionais em comparação com grupos controle da comunidade. Constatou-se que as mulheres inseridas nas prisões possuem uma prevalência maior de displasia cervical e câncer de colo uterino do que as mulheres na população em geral. A aceitação da triagem primária para o CCU varia entre as prisioneiras e nenhuma intervenção publicada no estudo revisional demonstrou melhorar a triagem dentro do sistema prisional. O tratamento e a conformidade com as recomendações de acompanhamento são extremamente pobres. ${ }^{28}$ Esses achados reforçam a necessidade de intervenções dentro dos sistemas prisionais, com estratégias efetivas em relação às medidas de triagem primária, detecção precoce e tratamento adequado para a neoplasia cervical uterina. ${ }^{23-25}$

Evidencia-se que essas mulheres possuem comportamentos de riscos, como tabagismo, relações sexuais precoces, uso raro de preservativos, baixa escolaridade e a multiplicidade de parceiro(a)s. ${ }^{4}$ Nessa investigação, encontrou-se um achado preocupante, uma vez que não foi relatada pelas participantes a realização de atividades educativas voltadas para prevenção de IST, CCU e oferta de informações a respeito dos tipos de neoplasias que acometem a população feminina durante a permanência dessas no período de reclusão nessa unidade prisional.

Há uma necessidade em realizar atividades educativas, preventivas e assistenciais direcionadas ao controle e rastreamento para o CCU nas instituições prisionais do país, 
adotando ações como as realizadas nas UBS, adaptando-as à realidade das prisões. Incluir essa população nas ações de prevenção para esse tipo de câncer é minimizar a vulnerabilidade e os fatores de risco aos quais estão expostas, que favorecem o surgimento e o desenvolvimento do CCU. ${ }^{4-6}$

Destaca-se a importância da atuação de equipes multiprofissionais nas unidades prisionais, para garantir o acesso aos bens e serviços de saúde bem como as informações referentes ao processo de saúde e doença, através de ações eficazes em relação à vulnerabilidade ${ }^{13-15}$ e às necessidades de saúde das mulheres reclusas. ${ }^{4-6,11,25}$

Conforme é apresentado na PNAISP, há cinco modalidades de EABp, as quais apresentam composição multiprofissional e com responsabilidade de articulação e prestação de atenção à saúde das pessoas em situação de reclusão, devendo realizar atividades nas unidades prisionais ou UBS a que estiverem vinculadas. O quantitativo de pessoas custodiadas e o perfil epidemiológico dessas pessoas é que determinará a modalidade da EABp e as respectivas cargas horárias. ${ }^{12}$

A EABp tipo I é composta de cinco profissionais - enfermeiro, médico, técnico ou auxiliar de enfermagem, cirurgião-dentista e técnico ou auxiliar de saúde bucal, com carga horária de seis horas semanais) e a EABp tipo I com saúde mental compõese de oito profissionais (cinco profissionais da EABp tipo I, somados a um psiquiatra ou médico com experiência em saúde mental e dois profissionais escolhidos entre as seguintes categorias: terapeuta ocupacional, fisioterapeuta, psicólogo, assistente social, farmacêutico ou enfermeiro com carga horária de seis horas semanais). A EABp tipo II é composta por oito profissionais, pela equipe básica de cinco profissionais associados a um psicólogo, um assistente social e um profissional escolhido entre as seguintes categorias: terapeuta ocupacional, psicólogo, fisioterapeuta, nutricionista, farmacêutico, assistente social ou enfermeiro. Esta modalidade de equipe cumprirá carga horária de 20 horas semanais. ${ }^{12}$

A EABp tipo II com saúde mental é composta basicamente pelos profissionais já citados, diferenciando-a pela quantidade de profissionais, em número de 11, e carga horária de 20 horas semanais. A EABp tipo III compõe-se basicamente dos mesmos profissionais EABp II com saúde mental, sendo formada por 11 profissionais com carga horária de 30 horas semanais. Percebe-se uma disparidade em relação à cobertura das equipes da PNAISP em todo o país, uma vez que a distribuição não é homogênea. Alguns estados possuem uma ampla cobertura, como Distrito Federal, Pernambuco e Mato Grosso do Sul, com 95\%, 85,1\% e 76\%, respectivamente, e estados como Amapá, Sergipe e Paraíba, com baixa cobertura entre $0 \%$ e $2,6 \%{ }^{12}$

O enfermeiro está presente em todas as modalidades da EABp e, em conjunto com os demais profissionais, necessita desenvolver e implementar ações efetivas direcionadas à saúde das mulheres em reclusão através de educação em saúde, com oferta de informações e orientações que contribuam com a promoção da saúde e a 
prevenção de doenças/agravos. ${ }^{12}$ Essas são oportunidades que possibilitam sensibilizar e orientar quanto aos hábitos e comportamentos para promover ou manter a saúde e o bem-estar. Uma vez que essas mulheres adquirem conhecimentos e informações, podem utilizá-las na adoção ou mudanças de hábitos de vida minimizando os fatores aos quais estão expostos durante a permanência no sistema prisional. ${ }^{3-6,23}$

Através de ações assistenciais e educativas, o enfermeiro que compõe essa equipe multiprofissional precisa sensibilizar as mulheres quanto à importância do exame citopatológico e adoção de medidas preventivas para evitar as IST, ${ }^{23-25}$ como a utilização de preservativos nas relações sexuais. ${ }^{4-6}$ Ressalta-se a vulnerabilidade das mulheres em reclusão para CCU, considerada como principal fator às infecções pelo HPV de transmissão predominantemente sexual. . $3,6,6,23,25$

\section{CONCLUSÃO}

Constataram-se fragilidades no sistema prisional no que concerne à implementação de atividades educativas, preventivas e assistenciais direcionadas às mulheres em relação à temática das IST e da prevenção do CCU, sendo necessário, aos gestores e profissionais de saúde que atuam nesses serviços, rever e planejar as ações de saúde a serem implementadas nas unidades prisionais, uma vez que a execução dessas é fragmentada, pontual e variável entre as unidades prisionais do mesmo estado.

O enfermeiro como integrante da equipe de saúde no sistema prisional e os demais profissionais das EABp devem aproveitar os espaços institucionais, como as bibliotecas, locais de trabalho, áreas recreativas (pátios) e mesmo as celas, para desenvolver atividades educativas que favoreçam a construção de conhecimentos e a sensibilização das mulheres em torno da temática saúde sexual e reprodutiva, visando à participação ativa e dialógica das reclusas em todo esse processo comunicacional e educativo.

É relevante o papel da equipe multiprofissional que atua nas prisões brasileiras e que compõe as EABp, as quais necessitam implementar atividades educativas, preventivas e assistenciais efetivas junto à população carcerária, com oferecimento de informações, orientações e esclarecimentos acerca da saúde reprodutiva e sexual, estimulando e proporcionando às reclusas a adoção de medidas de prevenção para IST, HIV/AIDS e doenças relacionadas ao gênero feminino (CCU e câncer de mama) da mesma maneira que são realizadas nas UBS da rede pública de saúde, visando à redução de doenças infectocontagiosas, adoecimento dessa população e a vulnerabilidade.

\section{REFERÊNCIAS}

1. Ministério da Justiça e Segurança Pública (Brasil). Departamento Penitenciário Nacional (DEPEN). Levantamento Nacional de Informações Penitenciárias INFOPEN. 
Painel interativo dezembro/2019[Internet]. 2019 jul-dez [citado 2020 nov 8].

Disponível em: http://antigo.depen.gov.br/DEPEN/depen/sisdepen/infopen/info pen.

2. Ministério da Justiça e Segurança Pública (BR). Departamento Penitenciário Nacional. Levantamento nacional de informações penitenciárias - InfoPen Atualização: junho de 2017 [Internet]. Brasília: Ministério da Justiça e Segurança Pública; 2017 [citado 2020 nov 8]. Available from: http://antigo.depen.gov.br/DEPEN/depen/sisdepen/ infopen/relatorios-sinteticos/infopen-jun-2017-rev-12072019-0721.pdf.

3. Oliveira KRV, Santos AAP, Silva JMO, Sanches METL, Albuquerque JM, Moraes MM. Comportamentos de saúde nas experiências sexuais de mulheres em situação de cárcere. Rev. Bras. Enferm. [Internet]. 2019 dez [citado 2020 nov 11]; 72(Suppl 3):88-95. Disponível em: https://www.scielo.br/scielo.php?script=sci_arttext\&pid= S003471672019000900088\&Ing =pt\&tlng=pt. Epub 2019 dez 13 https://doi.org/10. 1590/0034-7167-2018-0092.

4. Bossonario PA, Saita NM, Andrade RLP, Santos GP, Nemes MIB, Monroe AA. Assistência às pessoas com HIV/AIDS no cárcere: revisão da literatura. Texto contexto - enferm. [Internet]. 2020 [citado 2020 nov 8]; 29: e20180324. Disponível em: http://www.scielo.br/scielo.php?script=sci_arttext\&pid=S010407072020000 100504\&Ing=en. Epub 2020 fev 17 https://doi.org/10.1590/198026 5x-tce-2018-0324

5. Nicolau AIO, Aquino PS, Ximenes LB, Pinheiro KB. Determinantes sociais proximais relacionados ao câncer cervicouterino em mulheres privadas de liberdade.

Reme: Rev. Min. Enferm. [Internet]. 2015 set [citado 2020 nov 10]; 19(3):725-32. Disponível em: http://www.revenf.bvs.br/scielo.php?script=sci_arttext\&pid=S141527622015000300015\&lng=pt. http://dx.doi.org/10.5935/1415-2762.20150055.

6. Borges AP, Arenhardt K, Terças ACP, Cabral JF,Lucietto GC, Nascimento VF, et al. Perfil socioeconômico e sexual de mulheres privadas de liberdade. Rev enferm UFPE on line [Internet]. 2018 jul [citado 2020 nov 10]; 12(7): 1978-85. Disponível em: https:// periodicos.ufpe.br/revistas/revistaenfermagem/article/view/231408/29488.

7. Ormeno GR, Santini PM, Williams LCA. Fatores de risco e proteção vivenciados por mães encarceradas ao longo da vida. Estud pesqui psicol. [Internet]. 2017 [citado 2020 nov 11]; 17(2):514-34. Disponível em: https://www.epublicacoes.uerj.br/in dex.php/revispsi/article/view/37129/26223.

8. Alves RRF, Turchi MD, Santos LE, Guimarães BEM, Garcia MMD, Seixas MSC, et al. Prevalence, genotype profile and risk factors for multiple human papillomavirus cervical infection in unimmunized female adolescents in Goiânia, Brazil: a community-based study. BMC public health [Internet]. 2013 [cited 2020 nov 19]; 13(1):1041. Available from: https://www.ncbi.nlm.nih.gov/pmc/articles/ PMC3819257 /.

9. Damacena AM, Luz LL, Mattos IE. Rastreamento do câncer do colo do útero em Teresina, Piauí: estudo avaliativo dos dados do Sistema de Informação do Câncer do Colo do Útero, 2006-2013. Epidemiol. Serv. Saúde [Internet]. 2017 jan [citado 2020 
nov 19]; 26(1):71-80. Disponível em: http://scielo.iec.gov.br/scielo. php?script=sci_ arttext\&pid=S167949742017 000100071\&Ing=pt. http://dx.doi.org/ 10.5123/s167949742017000100008.

10. Ministério da Saúde (BR). Ministério da Justiça. Portaria Interministerial $n$ o 1, de 2 de janeiro de 2014: institui a Política Nacional de Atenção Integral à Saúde das Pessoas Privadas de Liberdade no Sistema Prisional (PNAISP) no âmbito do Sistema Único de Saúde (SUS). Diário Oficial da República Federativa do Brasil, Brasília, DF, 2014 jan 03. Seção 1, p. 18-21. Disponível em: http://bvsms.saude.gov.br/bvs/sal delegis/gm/2014/pri0001_02_01_2014.html.

11. Barsaglini R. Do plano à política de saúde no sistema prisional: diferenciais, avanços, limites e desafios. Physis [Internet], 2016 out [citado 2020 nov 19], 26(4):1429-39. Disponível em: http://www.scielo.br/scielo.php?script=sci arttext\&pid= S01037331201600 0401429\&lng=en. http://dx.doi.org/10.1590/ S010373312016000300019.

12. Ministério da Justiça e Segurança Pública (Brasil). Departamento Penitenciário Nacional. Coordenação de Saúde do DEPEN. Nota Técnica n. 23/2020/COS/CGCAP / DIRPP/ DEPEN/MJ [Internet]. 2020 [acesso em 2020 nov 19]. Disponível em: http:// antigo.depen.gov.br/DEPEN/SAUDEPRISIONALSEI_MJ11406541NotaTcnica.pdf.

13. Ayres JRCM, França Junior I, Calazans GJ, Saletti Filho HC. O conceito da vulnerabilidade e as práticas de saúde: novas perspectivas e desafios. In: Czeresnia D, Freitas CM (orgs). Promoção da saúde: conceitos, reflexões, tendências. 3 a reimp. Rio de Janeiro: FIOCRUZ, 2014, p. 117-39.

14. Ayres JRCM, Calazans GJ, Saletti Filho HC, França Junior I. Risco, vulnerabilidade e práticas de prevenção e promoção da saúde. In: Campos GWS, Minayo MCS, Akerman M, Drummond Júnior M, Carvalho YM, organizadores. Tratado de Saúde Coletiva. 2a ed. Rio de Janeiro: FIOCRUZ, 2012, p. 375-417.

15. Dimenstein M, Cirilo Neto M. Abordagens conceituais da vulnerabilidade no âmbito da saúde e assistência social. Pesquisas e Práticas Psicossociais [Internet]. 2020 [citado 2020 nov 10], 15(1): 1-17. Disponível em: http://pepsic.bvsalud.org/ scielo. php?script=sci_arttext \&pid=S180989082020000100002\&lng=pt\&tlng=pt.

16. Minayo MCS. O desafio do conhecimento: pesquisa qualitativa em saúde. 14a ed. São Paulo: HUCITEC; 2014.

17. Bardin L. L’analyse de Contenu. 1a ed. Lisboa: Edições 70; 2016.

18. Oliveira DC. Análise de conteúdo temático-categorial: uma proposta de sistematização. Rev. enferm. UERJ, Rio de Janeiro [Internet]. 2008 out-dez [citado 2020 nov 29]; 16(4):569-76. Disponível em: https://docplayer.com.br/264827Analise-de-conteudo-tematico-categorial-uma.html.

19. Lacerda MR, Constenaro RGS. Metodologias de Pesquisa para Enfermagem e Saúde: da teoria à prática. Porto Alegre (RS): Moriá; 2016. 
20. Minayo MCS. Amostragem e saturação em pesquisa qualitativa: consensos e controvérsias. Rev Pesqui Qualitativa [Internet]. 2017 abr [citado 2020 nov 29]; 5(7):112. Disponível em: https://editora.sepq.org.br/index.php/rpq/article/view/82.

21. Tong A, Sainsbury P, Craig J. Consolidated criteria for reporting qualitative research (COREQ): a 32- item checklist for interviews and focus groups. Int J Qual Health Care [Internet]. 2007 [cited 2020 nov 29]; 19(6):349-57. Available from: https://academic. oup.com/intqhc/article/19/6/349/1791966.

22. Conselho Nacional de Saúde (Brasil). Resolução no 466, de 12 de dezembro de 2012. Brasília, 2012 [citado 2020 set 24]. Disponível em: https://conselho.saude. gov.br/resolucoes/2012/Reso466.pdf.

23. Cordeiro EL, Silva TM, Silva LSR, Araújo PCE, Barros PF, Silva CM. Perfil epidemiológico dos detentos: patologias notificáveis. av. enferm. [Internet]. 2018 ago [citado 2020 nov 20]; 36(2):170-78. Disponível em: http://dx.doi. org/10.15446/av.enf erm.v36n2.68705.

24. Domingues RMSM, Leal MC, Pereira APE, Ayres B, Sánchez AR, Larouzé $B$. Prevalência de sífilis e infecção pelo HIV durante a gravidez em mulheres encarceradas e a incidência de sífilis congênita em partos em prisões no Brasil. Saúde Pública [Internet]. 2017 nov [citado 2020 nov 20]; 33(11):e00183616. Disponível em: http://www.scielo.br/scielo.php?script=sci_ arttext\&pid=S0102311X2017001105009\&Ing=en. Epub em 2017 nov 21.

25. Benedetti MSG, Nogami ASA, Costa BB, Fônseca HIF, Costa IS, Almeida IS, et al. Sexually transmitted infections in women deprived of liberty in Roraima, Brazil. Rev Saude Publica [Internet]. 2020 [citado 2020 nov 21]; 54(105):1-10. Disponível em: https://www.scielosp.org/pdf/rsp/2020.v54/105/en.

26. Sayyah M, Rahim F, Kayedani GA, Shirbandi K, Saki-Malehi A. Global View of HIV Prevalence in Prisons: A Systematic Review and Meta-Analysis. Iran J Public Health [Internet]. 2019 Feb [cited 2020 Dec 4]; 48(2):217-26. Available from: https:// pubmed.ncbi.nlm.nih.gov/31205875/.

27. Stone J, Fraser H, Lim AG, Walker JG, Ward Z, MacGregor L, et al. Incarceration history and risk of HIV and hepatitis $C$ virus acquisition among people who inject drugs: a systematic review and meta-analysis. The Lancet Infectious Diseases [Internet]. 2018 Dec [cited 2020 Dec 5]; 18(12):1397-1409. https://doi.org/10.1016/ S1473-3099(18)30469-9 Available from: https://jhu.pure.elsevier.com/en/ publications/incarceration-history-and-risk-of-hiv-and-hepatitis-c-virus-acqui.

28. Brousseau EC, Ahn S, Matteson KA. Cervical Cancer Screening Access, Outcomes, and Prevalence of Dysplasia in Correctional Facilities: A Systematic Review. J Womens Health (Larchmt) [Internet]. 2019 Dec [cited 2020 Dec 05]; 28 (12):1661-1669. Epub 2019 Apr 2. Available from: https://pubmed.ncbi.nlm.nih.gov/30939063/.

Submissão: agosto de 2017.

Aprovação: janeiro de 2021. 